\title{
Two hundred years of cancer epidemiology in Norway - before and during the NOFE era
}

\author{
Inger Torhild Gram and Eiliv Lund \\ Department of Community Medicine, UiT The Arctic University of Norway, Tromsø, Norway \\ E-mail: inger.gram@uit.no
}

This is an open access article distributed under the Creative Commons Attribution Licence, which permits unrestricted use, distribution, and reproduction in any medium, provided the original work is properly cited.

\section{INTRODUCTION}

In this chapter, we describe and reflect on some selected accomplishments made in cancer epidemiology during the last 200 years in Norway. We have a special emphasis on the last 25 years i.e. during NOFE's lifetime. We have tried to do this in a global context. Norwegian epidemiologists founded NOFE in 1990. At that time, the list of accomplishments in cancer epidemiology was not so extensive. Researchers in cancer epidemiology have made a lot of progress during the last 25 years. Worldwide, epidemiologists and data from Norway have played important roles and increased this research knowledge. It is essential that this research continue. Deaths from cancer will be the most common cause in Norway in the near future.

Tobacco use, particularly cigarette smoking should still be the main cancer control priority. We have chosen the relationship between smoking and cancer to picture the change that has been happening. In the 1990s results from single Norwegian cohort studies were published. Today, it is more common that data from the same cohorts are included in larger European, international and consortium collaborations. Results from Norwegian cohort studies have contributed to knowledge necessary for cancer prevention, as independent studies and in collaborations with researchers from other countries and fields in science. This chapter will introduce young researchers to some of the studies that are available for continued cancer research. We must apologize to those who played key roles in discoveries we have not described and whom we fail to mention.

\section{FREQUENT CANCERS GLOBALLY AND IN NORWAY TODAY}

Globally, as pointed out in the World Cancer Report from 2014, cancer is a major cause of morbidity and mortality. The approximately 14 million new cases and 8 million cancer related deaths, annually, are affecting populations in all countries and regions. In 2012, the three most common incident cancers were breast (25.2\% of the total), colorectal (9.2\%) and lung $(8.7 \%)$ cancer among women and lung $(16.7 \%$ of the total), prostate $(15.0 \%)$ and colorectal $(10.0 \%)$ cancer among men (1). These cancers were also the most frequent in Norway (2).

\section{CANCER EPIDEMIOLOGY IN NORWAY 1815-1990}

The first century of this period was totally dominated by infectious diseases as major causes of deaths. In Norway, tuberculosis was the main killer among young people. The only source of information on cancer was the death statistics. Until the 1930s, cancer was not a major cause of death. In the years before the second world war, the tuberculosis epidemic decreased rapidly and deaths from cancer increased, especially among the elderly. As in other European countries, the rapid increase in lung cancer among men became a particular concern. In Norway, from 1930 until 1950, Professor Kreyberg did an important work by establishing a systematic and reliable way to diagnose lung cancer. $\mathrm{He}$ documented the lung cancer epidemic (3), established different histo-pathological subtypes (4) and found differences in lung cancer incidence depending on urban and rural residence (5). It was not until the beginning of the fifties that researchers understood that the increase in lung cancer incidence was related to smoking. This was shown for Scandinavia in a comparative study of lung cancer in Finland and Norway (6).

The early work in cancer epidemiology depended on The Norwegian Radium Hospital (DNR), which opened in 1932. This was also the start of clinical research related to survival of breast cancer. The $25^{\text {th }}$ anniversary describes that from 1932 to 1951 , one out of four cancer cases was inoperable with a five-year survival of $8 \%$.

Two national cancer associations, founded in 1938 and in 1950, were important for cancer research in the postwar era. The first collected money for research with a particular focus on diet and risk of cancer. The latter collected money for basic cancer research conducted at DNR. In 1988, these two important organizations merged and is today the Norwegian Cancer Society (https://kreftforeningen.no/).

The Norwegian Government decided to establish the Cancer Registry of Norway, Institute of Populationbased Cancer Research in 1951. For cancer epidemiology, this resolution is the most important from the $20^{\mathrm{th}}$ century. The Registry is one of the oldest national cancer registries in the world. The Registry collects data based on compulsory notification of all newly diagnosed cancers from clinicians, pathologists and 

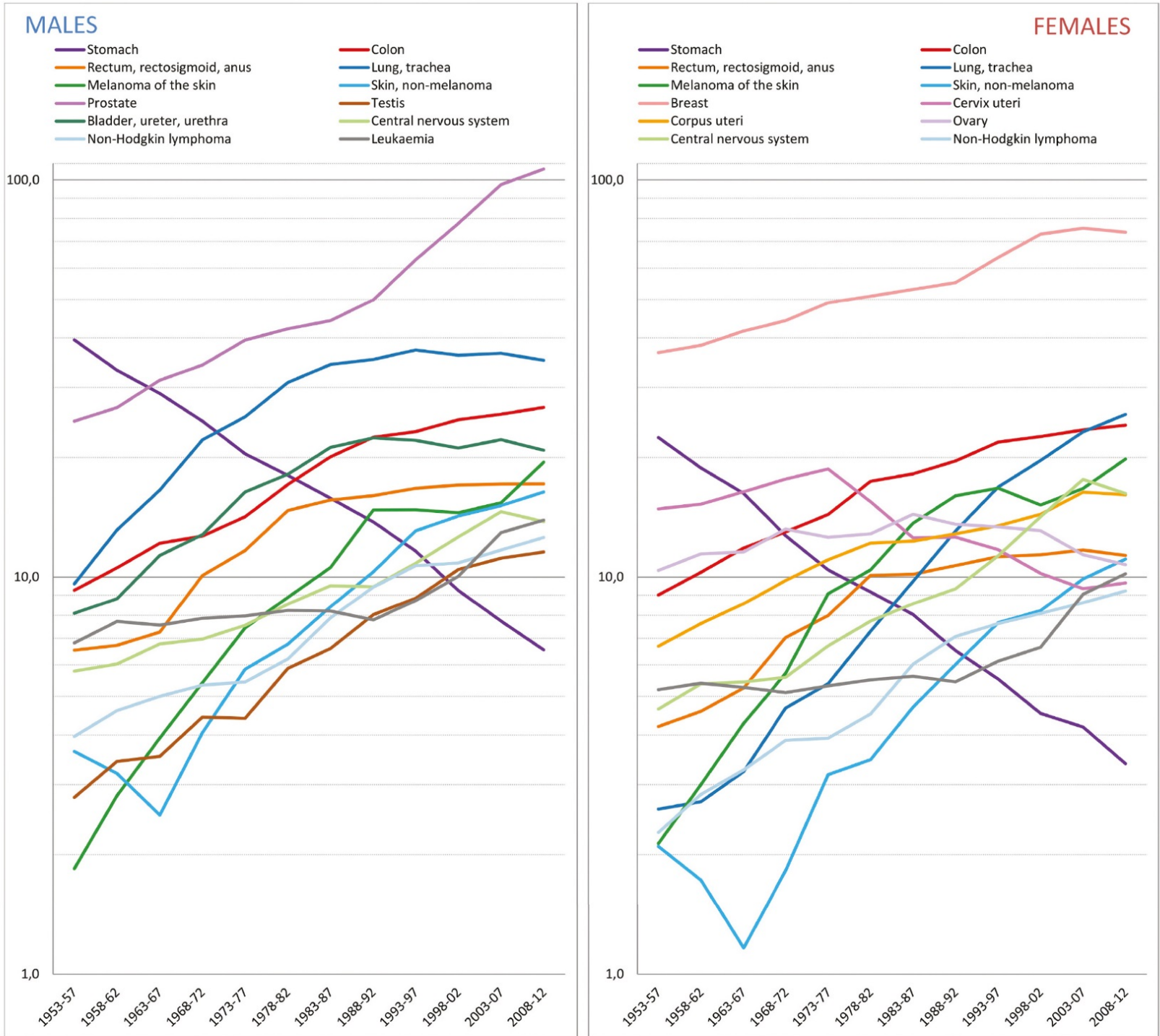

Figure 1. Time trends in age-standardised incidence rates (world) in Norway for selected cancers (semi log-scale), males (a) and females (b) 1953-2012 (2).

death certificates. The Cancer Registry has published descriptive statistics like annual incidence figures, periodically survival reports, and geographic analyses of incidence. In addition, several important classic descriptive studies were published on malignant melanoma and other sites of cancer (7). Figures $1 \mathrm{a}$ and $1 \mathrm{~b}$ show the cancer register data from 1953-2012 for both genders (2).

For more than thirty years, the Cancer Registry was the central institution for cancer epidemiology. Besides cancer statistics, the staff conducted several analytical projects, mainly within occupational cancer research. The projects were record-linkage studies between roosters of employed people and the cancer files. The first report was on the carcinogenic effect of nickel exposures (8) followed by many others (9). Through co-operation with the National Institute of Health, US, the first large collection of questionnaire information, the Migrant study, took place in Norway, England and the US. This study was also part of the first $\mathrm{PhD}$ at the Cancer Registry with its well-known finding of a protective effect of vitamin A on lung cancer risk (10). The Migrant study was originally a study of bronchitis, but later developed into a prospective cohort study of smoking and cancer (11).

Outside the Cancer Registry, one of the first large epidemiological studies was a Scandinavian population based case-control study on oral contraception and breast cancer in young women (12). During the late 1980s, epidemiologists realized the need for a change from case-control to cohort studies. The implementation of the first large multicenter studies started, like the European Prospective Investigation into Nutrition and Cancer (EPIC) (13). As part of this trend, the Norwegian Women and Cancer study (NOWAC or Kvinner og Kreft, http://site.uit.no/nowac) started enrollment in 1991, and became seven years later a part of EPIC (http://epic.iarc.fr/).

Another source of prospective data is the information collected as part of the national screening programs for cardiovascular diseases. Today the Cohort of Norway (CONOR) comprises ten of these cohorts (14). 
The health surveys covered both physical examinations, questionnaire data and blood samples. The latter forms today the Biobank Norway, described in another chapter. The JANUS biobank is another large population based biobank with blood samples from 317,000 Norwegians. Only cancer researchers may use this biobank. JANUS is unique regarding size and number of cancer cases. There were 65,000 donors with a cancer diagnosis, as of December 31, 2012 (http:// kreftregisteret.no/). The above-described collections of questionnaire information, measurements and biobanks have led to numerous Ph.D. theses and a broad scope of published papers in cancer epidemiology.

\section{CANCER SCREENING}

Cancer screening aims to reduce cancer specific mortality by prevention or early detection and treatment of invasive disease. In Norway screening programs for breast- and cervical cancer are implemented, while countries in Europe also recommend screening for colorectal cancer. Public health recommendations are based on the overall estimates of risk and benefit for the population. Lately, a lot of emphasis has been about the risks and benefits for the "average" person undertaking a screening examination.

Epidemiological studies from Norway have contributed to the controversial and passionate debate about mammography screening. Different research groups have published results based on data from the Norwegian Breast Cancer Screening Program (NBCSP, Figure 2) (15-17). An expert group, appointed by the Research Council of Norway, have recently evaluated these studies. The overall conclusion was that reduction in breast cancer mortality attributable to the implementation of the NBCSP is in the range of $20-30 \%$ for women aged 50-79 years, compared to a situation with no screening program (18). This is in agreement with the conclusion by the IARC expert group (19).

The NORCCAP study has investigated the benefits and costs of colorectal cancer screening in Norway. A recent publication from this group showed a significant $20 \%$ reduction in colorectal cancer incidence in a randomized trial with flexible sigmoidoscopy screening (20).

\section{SMOKING AND RISK OF CANCER}

Although the prevalence of daily smoking has been quite different for Norwegian men and women during the past sixty years, lung cancer has become the most common cancer killer for both (Figure 3) (21). Researchers identified lung cancer as the first of seventeen cancers that was causally related to smoking $(22,23)$. Studies from Norway, where today the majority of the middle-aged residents are ever (either former or current) smokers, have provided results helping to establish these relationships from as early as 1981 (11).

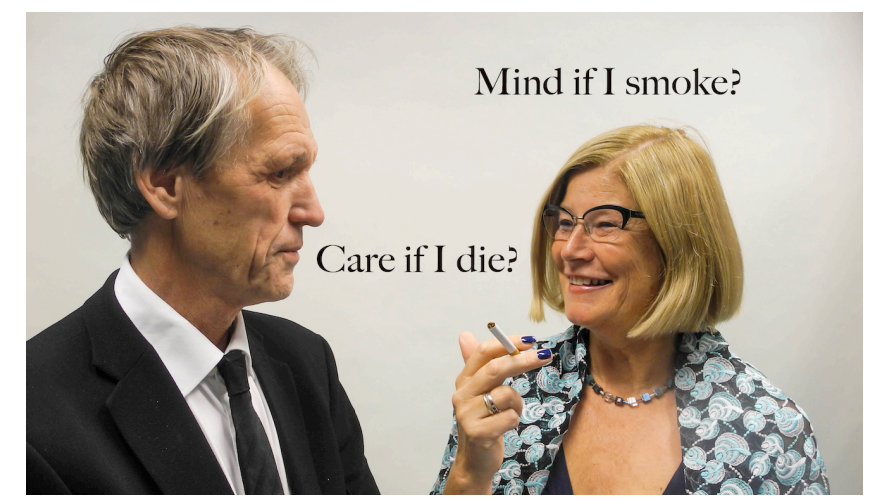

Figure 3. Smoking is the single most important cause of preventable cancer and cancer death.

In the now renowned Tromsø Studies, the first follow-up study was a cancer study revealing a positive association between smoking and risk of severe cervical dysplasia/cancer (24). Many years later, data from this study was included together with those from 22 other epidemiological studies finding an increased risk of cervical cancer of the same magnitude for current compared with never smokers as in the Troms $\varnothing$ study (25). More recently, an EPIC publication confirmed this association also in the context of different HPV infections (26). In 1996, results from a cohort of 26,000 Norwegians showed an increased risk of cancer of the cervix, pancreas, urinary bladder and cancers of the upper digestive and respiratory tract. (27). In 2004, IARC listed the following cancers i.e. oral cavity, oropharynx, nasopharynx, esophagus stomach, liver, pancreas, nasal cavity and sinuses, larynx, uterine cervix, kidney, lower urinary tract and myeloid leukemia to be smoking related cancers (28).

In 2008, results from the Swedish-Norwegian Women and Lifestyle Cohort found that smokers had an increased risk of mucinous ovarian cancer compared with never smokers (29). Results from EPIC (30) and from an international collaboration study (31) confirmed this. All three studies had individual data from the NOWAC cohort included. A similar example, where data from Norway have contributed, conveys to 
the smoking related increase of colorectal cancer. Female smokers had an increased risk of CRC compared with never smokers in the NOWAC cohort (32). The EPIC study found this association later for both genders (33). The Monograph from IARC published in 2012 and the US Surgeon General report from 2014 both list colorectal and mucinous ovarian cancer as causally related to smoking $(22,23)$. Recently, results from a cohort including health survey data from more than 600,000 Norwegians suggested that the increased risk of colon, but not rectal cancer, may be greater in women than in men $(34,35)$.

Collaborative efforts, including many participants and cancer cases, have power to show associations that single studies may not show, even if there is a real association. On the other hand, a huge sample size often means less detailed information. An example of a study that may have pointed us in the wrong direction, is the study on alcohol consumption and smoking and risk of breast cancer (36). This study included close to 60,000 breast cancer cases from 53 epidemiological studies. It found that alcohol consumption was to blame for $4 \%$ of the breast cancer cases, but that smoking did not increase breast cancer risk. In contrast to this, results from the NOWAC study updated with cancer cases until 2010, found that $9 \%$ of new breast cancer cases, i.e. one in eleven cases of the most common female cancer, could have been avoided if the women did not smoke (37).

The two expert reports described earlier, conclude that smoking may possibly increase breast cancer risk, but that there is not sufficient evidence to infer a causal relationship $(22,23)$. These reports included results from the Norwegian-Swedish cohort, finding an increased risk of breast cancer for women who started to smoke as teenagers (38). Unfortunately, the results from two large cohort studies, including close to 7,000 and 10,000 breast cancer cases, supporting a positive relationship between smoking and breast cancer, were published too late to be included in these evaluations. The first study included around 300,000 women from the Norwegian Health Screening Surveys (39) and the latter 300,000 women from EPIC (40). Results from the Breast and Prostate Cohort Consortium, examining gene-environment interactions in around 7,000 breast cancer cases could not convincingly explain if smoking is causally associated with breast cancer (41). Researchers in Norway have several opportunitis to continue to identify new cancers causally related to smoking (42).

\section{GENE-ENVIRONEMENT STUDIES IN CANCER RESEARCH}

The description of the genome in the years around 2000 resulted in an impressive optimism for the potential of identification of single nucleotide polymorphisms (SNPs) resulting in an increased risk for cancer. In the first few years after, a wave of positive results appeared when it was possible to do genome wide analyses, GWAS. It became relatively soon obvious; that most of these were false positive results due to lack of adequate handling of multiple testing. The introduction of correction for false discovery rate and other techniques soon changed the picture. At the same time, research groups built larger and larger consortiums to perform huge pooled analyses. Norwegian cohorts have participated mainly by delivering DNA to the collaborating centers.

The lung cancer consortium with thousands of cases and controls is one example of a huge research effort. Only one SNP displayed an increase in risk of lung cancer, which was approximately $80 \%$. Confronted with the risk increase of hundreds of percent for smoking this finding has little practical value (43). In the combined GWAS analysis of more than 60,000 breast cancer cases and the same number of controls, the results revealed 15 new susceptibility loci. However, these loci explained only about $2 \%$ of the variation in breast cancer risk (44). In a review, evaluating the GWAS results related to cancer, the conclusion was negative and a bit discouraging. The general advice to the researchers was to move on to functional genomics (45).

\section{HORMONES, BREAST CANCER AND MAMMOGRAPHIC DENSITIES}

NOWAC was the first nationally representative cohort study designed to examine cancer as outcome. Initially, NOWAC had a special focus on oral contraceptive use and risk of breast cancer, which at that time was a controversial topic (46). Today, both current OC-use and current postmenopausal hormone use are established risk factors for breast cancer. Studies from Norway have contributed to this knowledge (47-50). Norwegian scientists continue to raise new questions in this area: How is breast cancer risk among users of both hormonal medications (51)? Is there an antagonistic effect for OC-use and alcohol consumption on breast cancer risk (52)? Is it possible to explore the etiology of breast cancer through gene expression profiles from peripheral blood $(53,54)$ ? Epidemiologists have shown that menopausal hormone use also contributes to the breast cancer incidence trends in Norway $(55,56)$. Researchers have used mammographic densities, one of the strongest risk factors for breast cancer, as surrogate endpoints for breast cancer in an effort to understand the association between genes, endogenous and exogenous hormones (57-61) and risk of breast cancer.

\section{OBESITY AND RISK OF CANCER}

Assuming causality, obesity, or excess weight as measured by body mass index (BMI), could explain $41 \%$ of uterine, and $10 \%$ or more of kidney, liver, gall bladder and colon cancers (62). Several Norwegian studies have shown that BMI is an important predictor of cancer risk and cancer deaths. In a huge record 
linkage study that measured height and weight of two million Norwegian men and women from 1963 to 2001 , obesity was associated with a modest increase in risk of prostate (63) and an increased risk of colon cancer in men, and of gallbladder cancer in women (64). Obesity suggestively increased the risk of death from colon cancer in a cohort study where participants were aged 14-19 years at enrollment (65). In a recent cohort study, the authors observed that women had an increased risk of middle age death from cancer other than lung and breast cancer (66).

\section{PhysicAl ACTIVITY AND RISK OF CANCER}

All Norwegian cohort studies have collected information on physical activity measured as activity during leisure and work time, or using different scales. The Three County study found a protective effect of physical activity for prostate (67), colon (68) and breast (69) cancer. A recent study from NOWAC (70) did not confirm the latter association.

\section{ALCOHOL CONSUMPTION AND INFECTIONS AND RISK OF CANCER}

As summarized in the World Cancer Report, alcohol consumption causes cancer of the mouth, pharynx, larynx, esophagus, liver, colorectum and female breast. Globally, infections with Helicobacter pylori, hepatitis $\mathrm{B}$ and $\mathrm{C}$ viruses, and human papillomaviruses (HPV) are responsible for a huge (1.9 million cancer cases) number of gastric, liver and cervical cancer, respectively (1).There should be several opportunities to further examine the relationship between alcohol use and risk of cancer in the available Norwegian cohorts. Infectious agents as cause of cancer is not a major problem in Norway and have not been much examined. However, the transition from cytology to primary HPV screening programs will provide researchers with data related to cervical cancer.

\section{REPRODUCTIVE FACTORS AND RISK OF CANCER}

Already before 1990, epidemiologists created an important follow-up with interviews of more than 63,000 women with the objectives to study the associations between reproductive factors and cancer $(71,72)$. Later, studies based on records from different registers including more than 1 million women, have revealed new results and confirmed previous knowledge for the associations between reproductive factors and breast cancer, as well as cancer deaths (73-75). One registerbased study included all Norwegian women born in the period 1925 to 1979 , i.e. 1.7 million. The results based on close to 23,000 incident breast cancer cases, supported earlier findings that reproductive factors like parity, age at birth, and time since birth affect the risk of breast cancer. It also found that this differed by histological subtypes (76).

\section{RECORD LINKAGE STUDIES}

Researchers in Norway have unique opportunities to conduct record linkage studies. This possibility is often mentioned as a great advantage in discussions regarding Norwegian cancer research. We have already referred to some of them. However, the building of huge cohorts throughout the world has reduced the scientific importance of register-linkage studies. The main reason is the lack of adequate control for the increasing number of known confounders. In the future, we predict that these analyses will not be included in systematic reviews due to this short coming.

\section{Population attributable fraction (PAF)}

From a public health point of view, population attributable fraction (PAF) may be as important as the relative risk measure. This is because PAF more clearly express the potential for preventive endeavors. One example is that the burden of smoking related cancer and deaths from cancer may well be higher than previously anticipated (42). Results from NOWAC suggest that as many as one in four cancer deaths among middle-aged women could have been avoided if women in Norway did not smoke (77). Another study from NOWAC indicates that the PAF of breast cancer due to current use of menopausal hormones is as high as $27 \%$ (78). The underlying assumptions for PAF estimations are a causal relationship combined with calculations of PAF values with relative risk estimates from the same population. We will encourage young researchers to perform PAF analyses, whenever it is appropriate, so we increase our knowledge of opportunities for cancer prevention.

\section{VISIONS FOR THE FUTURE}

The ultimate goal is to understand cancer, combat the disease and bring it under control. Today we know that we cannot treat our way out of the cancer problem. Cancer epidemiology is the first step to understand the risk factors and causes of cancer and thereby the possibility for prevention. One important goal with this chapter has been to show the reader some of the contributions made by Norwegian researchers in cancer epidemiology. We also wanted to show how research in cancer epidemiology has moved from being "a one person operation", to research groups, national and international collaborations. A third important goal has been to give a short overview of the many possibilities for young researchers to get involved, utilize the abundance of data available and thereby increase our knowledge of the risk factors and causes of cancer. The ultimate goal is that this information will be used for preventive measures and thereby decrease the toll that cancer takes on the Norwegian as well as the global population. Today, there are many opportunities for young researchers in cancer epidemiology in Norway to make a difference! 


\section{REFERENCES}

1. Steward BW, Wild CP, ed. World Cancer Report 2014. Lyon: IARC, 2014.

2. Cancer Registry of Norway. Cancer in Norway 2012 - Cancer incidence, mortality, survival and prevalence in Norway. Oslo: Cancer Registry of Norway, 2014.

3. Kreyberg L. Lung cancer and tobacco smoking in Norway. Br J Cancer 1955; 9: 495-510.

4. Kreyberg L, Arnesen K. A survey of the histological types of one hundred primary epithelial lung tumours in Norway. Acta Unio Int Contra Cancrum 1953; 9: 598-602.

5. Kreyberg L. The geographical distribution of histological sub-groups of primary epithelial lung tumours in Norway. Br J Cancer 1954; 8: 599-604.

6. Magnus K, Pedersen E, Mork T, Hougen A, Bjelke E. Lung cancer in Finland and Norway: an epidemiological study. Acta Pathol Microbiol Scand 1969; Suppl. 1.

7. Magnus K. Incidence of malignant melanoma of the skin in Norway, 1955-1970. Variations in time and space and solar radiation. Cancer 1973; 32: 1275-86.

8. Pedersen E, Høgetveit AC, Andersen A. Cancer of respiratory organs among workers at a nickel refinery in Norway. Int J Cancer 1973; 12: 32-41.

9. Andersen A, Dahlberg BE, Magnus K, Wannag A. Risk of cancer in the Norwegian aluminium industry. Int J Cancer 1982; 29: 295-8.

10. Bjelke E. Dietary vitamin A and human lung cancer. Int J Cancer 1975; 15: 561-5.

11. Lund $\mathrm{E}$, Zeiner-Henriksen $\mathrm{T}$ [Smoking as a risk factor for different cancer forms among 26,000 Norwegian men and women. A comparison of a material of smokers from the Norwegian Cancer Registry]. Tidsskr Nor Lageforen 1981; 101: 1937-40.

12. Meirik O, Lund E, Adami HO, Bergström R, Christoffersen T, Bergsjö P. Oral contraceptive use and breast cancer in young women. A joint national case-control study in Sweden and Norway. Lancet 1986; 334: 650-4.

13. Riboli E, Hunt KJ, Slimani N, Ferrari P, Norat T, Fahey M, et al. European Prospective Investigation into Cancer and Nutrition (EPIC): study populations and data collection. Public Health Nutr 2002; 5: 1113-24.

14. Næss Ø, Søgaard AJ, Arnesen E, Beckstrøm AC, Bjertness E, Engeland A, et al. Cohort profile: cohort of Norway (CONOR). Int $J$ Epidemiol 2008; 37: 481-5.

15. Hofvind S, Ursin G, Tretli S, Sebuødegård S, Møller B. Breast cancer mortality in participants of the Norwegian Breast Cancer Screening Program. Cancer 2013; 119: 3106-12.

16. Olsen AH, Lynge E, Njor SH, Kumle M, Waaseth M, Braaten T, et al. Breast cancer mortality in Norway after the introduction of mammography screening. Int J Cancer 2013; 132: 208-14.

17. Weedon-Fekjær H, Romundstad PR, Vatten LJ. Modern mammography screening and breast cancer mortality: population study. BMJ 2014; 348: 3701-6.

18. Research-based evaluation of the Norwegian Breast Cancer Screening Program. Oslo: The Research Council of Norway, 2015 May 31.

19. Lauby-Secretan B, Scoccianti C, Loomis D, Benbrahim-Tallaa L, Bouvard V, Bianchini F, et al. Breastcancer screening - viewpoint of the IARC Working Group. $N$ Engl J Med 2015: 372: 2353-8.

20. Holme Ø, Bretthauer M, Eide TJ, Løberg EM, Grzyb K, Løberg M, et al. Long-term risk of colorectal cancer in individuals with serrated polyps. Gut 2015; 64: 929-36.

21. Cancer Registry of Norway. Cancer in Norway 2013 - Cancer incidence, mortality, survival and prevalence in Norway. Oslo, Norway, 2015.

22. International Agency for Research on Cancer. International Agency for Research on Cancer (IARC) monographs on the evaluation of carcinogenic risks to humans. Vol $100 \mathrm{E}$ : a review of human carcinogens: personal habits and indoor combustions. Lyon: International Agency for Research on Cancer, 2012.

23. U.S Deparment of Health and Human Services. The Health Consequences of Smoking - 50 Years of Progress: A Report of the Surgeon General. Atlanta, GA: 2014.

24. Gram IT, Austin H, Stalsberg H. Cigarette smoking and the incidence of cervical intraepithelial neoplasia, grade III, and cancer of the cervix uteri. Am J Epidemiol 1992; 135: 341-6.

25. International Collaboration of Epidemiological Studies. Carcinoma of the cervix and tobacco smoking: Collaborative reanalysis of individual data on 13,541 women with carcinoma of the cervix and 23,017 women without carcinoma of the cervix from 23 epidemiological studies. Int J Cancer 2006; 118: 1481-95.

26. Roura E, Castellsague X, Pawlita M, Travier N, Waterboer T, Margall N, et al. Smoking as a major risk factor for cervical cancer and pre-cancer: Results from the EPIC cohort. Int J Cancer 2014; 135: 453-66.

27. Engeland A, Andersen A, Haldorsen T, Tretli S. Smoking habits and risk of cancers other than lung cancer: 28 years' follow-up of 26,000 Norwegian men and women. Cancer Causes Control 1996; 7: 497-506.

28. IARC. IARC Monographs on the Evaluation of Carcinogenic Risks to Humans. Tobacco Smoke and Involuntary Smoking. Lyon: IARC Press, 2004.

29. Gram IT, Braaten T, Adami HO, Lund E, Weiderpass E. Cigarette smoking and risk of borderline and invasive epithelial ovarian cancer. Int $J$ Cancer 2008; 122: 647-52. 
30. Gram IT, Lukanova A, Brill I, Braaten T, Lund E, Lundin E, et al. Cigarette smoking and risk of histological subtypes of epithelial ovarian cancer in the EPIC cohort study. Int J Cancer 2012; 130: 2204-10.

31. Beral V, Gaitskell K, Hermon C, Moser K, Reeves G, Peto R. Ovarian cancer and smoking: individual participant meta-analysis including 28,114 women with ovarian cancer from 51 epidemiological studies. Lancet Oncol 2012; 13: 946-56.

32. Gram IT, Braaten T, Lund E, Le Marchand L, Weiderpass E. Cigarette smoking and risk of colorectal cancer among Norwegian women. Cancer Causes Control 2009; 10: 895-903.

33. Leufkens AM, van Duijnhoven FJ, Siersema PD, Boshuizen HC, Vrieling A, Agudo A, et al. Cigarette smoking and colorectal cancer risk in the European prospective investigation into cancer and nutrition study. Clin Gastroenterol Hepatol 2011; 9: 137-44.

34. Parajuli R, Bjerkaas E, Tverdal A, Selmer R, Le Marchand L, Weiderpass E, et al. The increased risk of colon cancer due to cigarette smoking may be greater in women than men. Cancer Epidemiol Biomarkers Prev 2013; 22: 862-71.

35. Parajuli R, Bjerkaas E, Tverdal A, Le ML, Weiderpass E, Gram IT. Smoking increases rectal cancer risk to the same extent in women as in men: results from a Norwegian cohort study. BMC Cancer 2014,14: 321.

36. Hamajima N, Hirose K, Tajima K, Rohan T, Calle EE, Heath CW, Jr., et al. Alcohol, tobacco and breast cancer - collaborative reanalysis of individual data from 53 epidemiological studies, including 58,515 women with breast cancer and 95,067 women without the disease. Br J Cancer 2002; 87: 1234-45.

37. Gram IT, Little M, Lund E, Braaten T. Smoking before first childbirth may explain some of the increase in breast cancer diagnosed before 50 years of age. Abstract, Proceedings AACR Annual Meeting, San Diego, California, USA, 2014.

38. Gram IT, Braaten T, Terry PD, Sasco AJ, Adami HO, Lund E, et al. Breast cancer risk among women who start smoking as teenagers. Cancer Epidemiol Biomarkers Prev 2005; 14: 61-6.

39. Bjerkaas E, Parajuli R, Weiderpass E, Engeland A, Maskarinec G, Selmer R, et al. Smoking duration before first childbirth: an emerging risk factor for breast cancer? Results from 302,865 Norwegian women. Cancer Causes Control 2013; 24: 1347-56.

40. Dossus L, Boutron-Ruault MC, Kaaks R, Gram IT, Vilier A, Fervers B, et al. Active and passive cigarette smoking and breast cancer risk: results from the EPIC cohort. Int J Cancer 2014; 134: 1871-88.

41. Cox DG, Dostal L, Hunter DJ, Le Marchan L, Hoover R, Ziegler RG, et al. N-acetyltransferase 2 polymorphisms, tobacco smoking, and breast cancer risk in the breast and prostate cancer cohort consortium. Am J Epidemiol 2011; 174: 1316-22.

42. Carter BD, Abnet CC, Feskanich D, Freedman ND, Hartge P, Lewis CE, et al. Smoking and mortality beyond established causes. $N$ Engl J Med 2015; 372: 631-40.

43. Hung RJ, McKay JD, Gaborieau V, Boffetta P, Hashibe M, Zaridze D, et al. A susceptibility locus for lung cancer maps to nicotinic acetylcholine receptor subunit genes on 15q25. Nature 2008; 452: 633-7.

44. Freedman ML, Monteiro AN, Gayther SA, Coetzee GA, Risch A, Plass C, et al. Principles for the postGWAS functional characterization of cancer risk loci. Nat Genet 2011; 43: 513-8.

45. Michailidou K, Hall P, Gonzalez-Neira A, Ghoussaini M, Dennis J, Milne RL, et al. Large-scale genotyping identifies 41 new loci associated with breast cancer risk. Nat Genet 2013; 45: 353-2.

46. Lund E, Meirik O, Adami HO, Bergström R, Christoffersen T, Bergsjö P. Oral contraceptive use and premenopausal breast cancer in Sweden and Norway: possible effects of different pattern of use. Int J Epidemiol 1989; 18: 527-32.

47. Kumle M, Weiderpass E, Braaten T, Persson I, Adami HO, Lund E. Use of oral contraceptives and breast cancer risk: The Norwegian-Swedish Women's Lifestyle and Health Cohort Study. Cancer Epidemiol Biomarkers Prev 2002; 11: 1375-81.

48. Dumeaux V, Alsaker E, Lund E. Breast cancer and specific types of oral contraceptives: a large Norwegian cohort study. Int J Cancer 2003; 105: 844-50.

49. Bakken K, Lund E, Eggen AE. The impact of hormone replacement therapy on the incidence of breast cancer in Norway. J Clin Oncol 2005; 23: 3636-7.

50. Bakken K, Fournier A, Lund E, Waaseth M, Dumeaux V, Clavel-Chapelon F, et al. Menopausal hormone therapy and breast cancer risk: impact of different treatments. The European Prospective Investigation into Cancer and Nutrition. Int J Cancer 2011; 128: 144-56.

51. Lund E, Bakken K, Dumeaux V, Andersen V, Kumle M. Hormone replacement therapy and breast cancer in former users of oral contraceptives - The Norwegian Women and Cancer study. Int J Cancer 2007; 121: 645-8.

52. Dumeaux V, Lund E, Hjartaker A. Use of oral contraceptives, alcohol, and risk for invasive breast cancer. Cancer Epidemiol Biomarkers Prev 2004; 13: 1302-7.

53. Dumeaux V, Børresen-Dale AL, Frantzen JO, Kumle M, Kristensen VN, Lund E. Gene expression analyses in breast cancer epidemiology: the Norwegian Women and Cancer postgenome cohort study. Breast Cancer Res 2008; 10: R13. 
54. Dumeaux V, Ursini-Siegel J, Flatberg A, Fjøsne HE, Frantzen JO, Holmen MM, et al. Peripheral blood cells inform on the presence of breast cancer: a population-based case-control study. Int J Cancer 2015; 136: 65667.

55. Hofvind S, Sakshaug S, Ursin G, Graff-Iversen S. Breast cancer incidence trends in Norway - explained by hormone therapy or mammographic screening? Int J Cancer 2012; 130: 2930-8.

56. Weedon-Fekjær H, Bakken K, Vatten LJ, Tretli S. Understanding recent trends in incidence of invasive breast cancer in Norway: age-period-cohort analysis based on registry data on mammography screening and hormone treatment use. BMJ 2012; 344: e299.

57. Stuedal A, Ursin G, Veierød MB, Bremnes Y, Reseland JE, Drevon CA, et al. Plasma levels of leptin and mammographic density among postmenopausal women: a cross-sectional study. Breast Cancer Res 2006; 8: R55.

58. Bremnes Y, Ursin G, Bjurstam N, Lund E, Gram IT. Different types of postmenopausal hormone therapy and mammographic density in Norwegian women. Int J Cancer 2007; 120: 880-4.

59. Biong M, Gram IT, Brill I, Johansen F, Solvang HK, Alnæs GI, et al. Genotypes and haplotypes in the insulin-like growth factors, their receptors and binding proteins in relation to plasma metabolic levels and mammographic density. BMC Med Genomics 2010; 3: 9.

60. Couto E, Qureshi SA, Hofvind S, Hilsen M, Aase H, Skaane P, et al. Hormone therapy use and mammographic density in postmenopausal Norwegian women. Breast Cancer Res Treat 2012; 132: 297-305.

61. Frydenberg H, Flote VG, Iversen A, Finstad SE, Furberg AS, Torjesen PA, et al. Insulin-like growth factor-1, growth hormone, and daily cycling estrogen are associated with mammographic density in premenopausal women. Cancer Causes Control 2014; 25: 891-903.

62. Bhaskaran K, Douglas I, Forbes H, dos-Santos-Silva I, Leon DA, Smeeth L. Body-mass index and risk of 22 specific cancers: a population-based cohort study of 5.24 million UK adults. Lancet 2014; 384: 755-65.

63. Engeland A, Tretli S, Bjørge T. Height, body mass index, and prostate cancer: a follow-up of 950000 Norwegian men. Br J Cancer 2003; 89: 1237-42.

64. Engeland A, Tretli S, Austad G, Bjørge T. Height and body mass index in relation to colorectal and gallbladder cancer in two million Norwegian men and women. Cancer Causes Control 2005; 16: 987-96.

65. Bjorge T, Engeland A, Tverdal A, Smith GD. Body mass index in adolescence in relation to cause-specific mortality: a follow-up of 230,000 Norwegian adolescents. Am J Epidemiol 2008; 168: 30-7.

66. Hjellvik V, Selmer R, Gjessing HK, Tverdal A, Vollset SE. Body mass index, smoking, and risk of death between 40 and 70 years of age in a Norwegian cohort of 32,727 women and 33,475 men. Eur J Epidemiol 2013; 28: 35-43.

67. Thune I, Lund E. Physical activity and the risk of prostate and testicular cancer: a cohort study of 53,000 Norwegian men. Cancer Causes Control 1994; 5: 549-56.

68 Thune I, Lund E. Physical activity and risk of colorectal cancer in men and women. Br J Cancer 1996; 73: 1134-40.

69. Thune I, Brenn T, Lund E, Gaard M. Physical activity and the risk of breast cancer. N Engl J Med 1997; 336: $1269-75$

70. Borch KB, Lund E, Braaten T, Weiderpass E. Physical activity and the risk of postmenopausal breast cancer the Norwegian Women and Cancer Study. J Negat Results Biomed 2014; 13: 3.

71. Kvale G, Heuch I, Eide GE. A prospective study of reproductive factors and breast cancer. I. Parity. Am $J$ Epidemiol 1987; 126: 831-41.

72. Kvale G, Heuch I. A prospective study of reproductive factors and breast cancer. II. Age at first and last birth. Am J Epidemiol 1987; 126: 842-50.

73. Lund E. Childbearing and breast cancer. Lancet 1993; 341: 502-3.

74. Lund E. Number of children and death from hormone-dependent cancers. Int J Cancer 1990; 46: 998-1000.

75. Albrektsen G, Heuch I, Kvåle G. Reproductive factors and incidence of epithelial ovarian cancer: a Norwegian prospective study. Cancer Causes Control 1996; 7: 421-7.

76. Albrektsen G, Heuch I, Thoresen SØ. Histological type and grade of breast cancer tumors by parity, age at birth, and time since birth: a register-based study in Norway. BMC Cancer 2010; 10: 226.

77. Gram IT, Sandin S, Braaten T, Lund E, Weiderpass E. The hazards of death by smoking in middle-aged women. Eur J Epidemiol 2013; 28: 799-806.

78. Bakken K, Alsaker E, Eggen AE, Lund E. Hormone replacement therapy and incidence of hormonedependent cancers in the Norwegian Women and Cancer study. Int J Cancer 2004; 112: 130-4. 